\title{
ESTUDO EXPERIMENTAL DAS PROPRIEDADES FÍSICAS DE ARGAMASSAS
}

COM ADIÇÃO DE RESÍDUOS DE CERÂMICAS VERMELHAS RECICLADAS

\author{
Bruno Silva Mendes \\ brunosm85@hotmail.com \\ Edilberto Vitorino de Borja \\ Professor do Departamento de Construção Civil do CEFET-RN \\ edilberto@cefetrn.br
}

\section{RESUMO}

O uso de argamassas como meio de reciclagem materiais orgânico e inorgânicos não é de hoje. Vários estudos já foram realizados nesta área, já que a sociedade e a indústria da construção civil estão sempre procurando desenvolver novas tecnologias. Tendo em vista essa visão que este trabalho foi desenvolvido, propondo analisar as propriedades físicas de argamassas de revestimento de alvenaria produzidas a partir de diferentes proporções de resíduos de cerâmicas vermelhas recicladas (RCV) através do processo de trituração, objetivando, assim, a redução dos custos de produção e da quantidade desses resíduos descartados no ambiente. Para se realizar a proposta estabelecida, os seguintes pontos foram destacados como objetivos principais: determinação das proporções otimizadas do "novo composto" de forma a se enquadrar nos parâmetros normativos em vigor referente às argamassas; analisar o comportamento do resíduo de cerâmica vermelha reciclada como agregado miúdo em argamassa de assentamento e/ou revestimento no que diz respeito as suas propriedades físicas; identificar a influência da quantidade de resíduos de cerâmicas vermelhas nas quatro proporções previamente estabelecidas (5\%, 10\%, 15\% e 20\%) em substituição ao agregado miúdo (cal) mantendo-se o mesmo fator água / cimento. Para tanto, foram realizados ensaios no estado fresco (índice de consistência, teor de ar incorporado e densidade de massa fluida). Os resultados demonstraram que a presença do RCV na argamassa aumenta o índice de consistência e o teor de ar incorporado e reduz a densidade de massa. As propriedades físicas das argamassas no estado fresco são otimizadas coma a adição do RCV.

Palavras-chave: reciclagem, RCV, argamassa. 


\section{ESTUDO EXPERIMENTAL DAS PROPRIEDADES FÍSICAS DE ARGAMASSAS} COM ADIÇÃO DE RESÍDUOS DE CERÂMICAS VERMELHAS RECICLADAS

\section{INTRODUÇÃO}

A geração de resíduos da construção civil (RC) é motivo de grande preocupação para a população, no que diz a respeito à preservação ambiental, e para as construtoras, a custos para se dar um fim a esses resíduos.

De acordo com a resolução $n^{0}$. 307 (2001) do CONAMA, os resíduos da construção civil são os provenientes de construções, reformas, reparos e demolições de obras de construção civil, e os resultantes da preparação e da escavação de terrenos, tais como: tijolos, blocos cerâmicos, concreto em geral, solos, rochas, metais, resinas, colas, tintas, madeiras e compensados, forros, argamassa, gesso, telhas, pavimento asfáltico, vidros, plásticos, tubulações, fiação elétrica etc., comumente chamados de entulhos de obras, caliça ou metralha.

O desenvolvimento tecnológico de processos associados à reciclagem de RC passa a ter hoje enorme relevância. O aumento no descarte de RC, bem como os problemas advindos da exaustão de matérias-primas naturais, vem impulsionando os estudos sobre o aproveitamento desses resíduos como novos materiais, reduzindo o seu impacto ambiental e viabilizando a redução de custos industriais.

A reciclagem de resíduos de construção encontra-se em estágio relativamente avançado. Muitas universidades e centros de tecnologia possuem grupos muito ativos no estudo dos resíduos de construção, seja no aspecto de redução de sua geração durante a atividade de construção, de políticas públicas para o manuseio dos resíduos e ainda de tecnologias para a reciclagem.

A indústria da Construção Civil tem um grande potencial para a solução desses problemas, pois apresenta uma enorme viabilidade de incorporação desses resíduos nos materiais de construção, possibilitando, ainda, a redução nos custos dos produtos da construção. A argamassa, depois do concreto, vem se tornando um importante aliado na reciclagem de RC.

Como definição, argamassa é a mistura intima de um ou mais aglomerantes, agregado miúdo (areia) e água. Além destes componentes essenciais, presentes nas argamassas podem ainda ser adicionados produtos especiais, com a finalidade de melhorar ou conferir determinadas propriedades ao conjunto, denominado aditivo. As argamassas distinguem-se por apresentarem características plásticas e adesivas quando de sua aplicação e por tornarem-se rígidas e resistentes após certo período de tempo. Estes fatos determinam seus principais empregos na construção civil.

A proposta deste trabalho se resume em analisar as influências que o resíduo de cerâmica vermelha reciclada (RCV) promove nas propriedades físicas de argamassas para revestimento no seu estado fresco.

\section{REVISÃO BIBLIOGRÁFICA}

A reciclagem de resíduos de construção e demolição (RCD) teve início no Brasil em 1991 quando foi instalada a primeira usina na cidade de Itatinga (estado de São Paulo), com a 
capacidade de reciclagem de 100 toneladas por dia. O material reciclado foi inicialmente utilizado como base na pavimentação de ruas e estradas.

Voltado para esta necessidade ecológica devido ao grande impacto ambiental que esses resíduos estão causando, pesquisas têm alargado a sua utilização em argamassas e concretos, cujos agregados naturais têm sido substituídos por agregados reciclados ou em combinação de ambos.

A reciclagem de RCD é, de forma simplificada, um beneficiamento mineral composta de um conjunto de operações unitárias com o objetivo de se obter características específicas de uma matéria-prima como separação dos seus constituintes minerais, adequação de tamanho, etc. (ÂNGULO, KAHN, JOHN, ULSEN: 2005).

A composição dos resíduos de construção e demolição é bastante diversificada, constituída praticamente de restos de todos os materiais da construção, e principalmente por material não mineral, sendo que na sua maior parte é constituída por argamassas e em menor quantidade por pedras. A composição química esta vinculada a cada um dos diferentes elementos que o constitui.

Como na aplicação de argamassas de revestimento ou de assentamento, todas as atividades na construção civil geram grandes quantidades de entulho, pois há um alto índice de perda no setor, em média o entulho gerado corresponde a $50 \%$ do material utilizado. No Brasil, estima-se que é gerado anualmente algo em torno de 68,5 milhões de toneladas de RCD.

No Brasil, os mercados das matérias-primas da indústria cerâmica, de forma isolada, não são capazes de absorver integralmente o RCD. Mas, caso haja maior interesse econômico e/ou ambiental, ele pode ser explorado. Uma parcela de 30\% dos mercados das matériasprimas de cerâmica vermelha, de cerâmica de revestimento e de cimento poderia empregar algo em torno de 60\% de todo o RCD. (ÂNGULO, KAHN, JOHN, ULSEN: 2005).

VIEIRA (2005) estudou a aplicação do RCV como substituição pozolânica em argamassas, concluiu ser viável tecnicamente esta possibilidade. VEIRA (2005) verificou que o resíduo tem índice de atividade pozolânica satisfatórios, tanto para sistemas com cal quanto cimento, apenas para finuras superiores a $5000 \mathrm{~cm}^{2} / \mathrm{g}$. No estudo foram analisadas argamassas com teor de $0 \%, 20 \%$ e $40 \%$ de RCV, em peso.

\section{MATERIAIS E MÉTODOS}

\subsection{Materiais}

O estudo foi realizado a partir de compósitos de argamassa para revestimentos com adição de resíduos de cerâmica vermelha reciclada. A argamassa foi produzida nos laboratórios de Materiais de Construção do CEFET-RN, a partir da mistura, de cimento (CPII Z-32 RS), cal hidratada, areia proveniente de leito de lago do município de Igrejinha, e resíduo de cerâmica vermelha (proveniente da quebra ou empena de telhas de cerâmica vermelha) da fábrica de cerâmicas de Parelhas-RN. A caracterização dos materiais utilizados está listada na Tabela 1. 
MENDES e BORJA (2007)

Tabela 1 - Características físicas dos materiais utilizados

\begin{tabular}{|c|c|c|c|c|}
\hline MATERIAL & $\begin{array}{c}\text { Massa } \\
\text { Unitária - } \\
\text { NBR 7251 } \\
\left(\mathrm{g} / \mathbf{c m}^{3}\right)\end{array}$ & $\begin{array}{c}\text { Massa } \\
\text { Específica - } \\
\text { NBRNM52 } \\
\left(\mathrm{g} / \mathrm{cm}^{3}\right)\end{array}$ & $\begin{array}{c}\text { Módulo de Finura } \\
- \\
\text { NBR } 7217\end{array}$ & $\begin{array}{c}\text { Dimensão Máxima } \\
- \\
\text { NBR } 7217 \\
\text { (mm) }\end{array}$ \\
\hline Cimento & 1,25 & 3,00 & & \\
\hline Cal & 0,46 & 2,02 & & \\
\hline Areia & 1,55 & 2,62 & 2,37 & 4,8 \\
\hline $\mathrm{RCV}$ & 1,21 & 2,63 & 1,93 & 2,4 \\
\hline
\end{tabular}

Depois de realizada a caracterização dos materiais, foram definidos três traços de argamassa, representados na Tabela 2, para a obtenção do traço de referência. Durante a produção das argamassas o TR 2 apresentou características favoráveis para o estudo, tais como: melhor trabalhabilidade e maior coesão entre os materiais constituintes.

Tabela 2 - Traços de estudo

\begin{tabular}{l|c|c|c}
\hline \multirow{2}{*}{ MATERIAIS } & \multicolumn{3}{|c}{ TRAÇO (GRAMAS) } \\
\cline { 2 - 4 } & TR 1 & TR 2 & TR 3 \\
\hline Cimento & 121,00 & 141,50 & 130,50 \\
\hline Cal & 107,00 & 127,50 & 116,50 \\
\hline Areia & 1165,00 & $1.165,00$ & $1.165,00$ \\
\hline Água & 240,00 & 240,00 & 240,00 \\
\hline
\end{tabular}

Obtido o traço de referência, foram definidos mais quatro traços de argamassa, sendo um deles com $5 \%$, outro com $10 \%$, outro com $15 \%$ e outro com $20 \%$ de adição de RCV em substituição à cal. Os traços foram descritos na Tabela 3. A quantidade de material descrita nesta tabela para cada traço foi referente ao molde de três corpos de prova cilíndricos.

Tabela 3 - Materiais utilizados no traço de argamassa com resíduos

\begin{tabular}{l|c|c|c|c}
\hline \multirow{2}{*}{ MATERIAL } & \multicolumn{4}{|c}{ TRAÇOS COM ADIÇÃO DE RCV (GRAMAS) } \\
\cline { 2 - 5 } & $\mathbf{5 \%}$ & $\mathbf{1 0 \%}$ & $\mathbf{1 5 \%}$ & $\mathbf{2 0 \%}$ \\
\hline Cimento & 141,50 & 141,50 & 141,50 & 141,50 \\
\hline Cal & 121,12 & 114,75 & 108,38 & 102,00 \\
\hline Areia & $1.165,00$ & $1.165,00$ & $1.165,00$ & $1.165,00$ \\
\hline RCV & 6,38 & 12,75 & 19,12 & 25,5 \\
\hline Água & 240,00 & 240,00 & 240,00 & 240,00 \\
\hline
\end{tabular}




\subsection{Métodos}

\subsubsection{Preparo das Argamassas}

As argamassas foram preparadas fazendo-se a mistura em massa de cimento, cal hidratada, areia e água, na argamassa de traço de referência, e, posteriormente, na produção dos outros traços foi adicionado o RCV nas proporções pré-estabelecidas. A homogeneização dos materiais foi realizada em um misturador mecânico de eixo vertical, de movimento planetário, palheta única, volume de 5 litros e velocidade de $62 \pm 5$ rpm.

O procedimento de mistura seguido para a produção das argamassas é definido pela NBR 13276, o qual é resumido na Tabela 4.

Tabela 4 - Procedimento de produção de argamassa no misturador mecânico

Colocar os materiais constituintes, exceto o cimento e a água, em quantidades definidas pelo seu traço no misturador desligado;

Com uma espátula, fazer uma homogeneização do material seco e depois adicionar a água;

Ligar o misturador em velocidade baixa e deixar misturar por $4 \mathrm{~min}$;

Ao final dos 4 min, desligar o misturador e verificar, com a espátula, se há material aderido ao fundo do misturador;

Retirar o material, pesá-lo e deixar em maturação por um período de 16 a 24 horas;

Após a maturação, pesar o material novamente e, se necessário, repor a quantidade de água evaporada;

Colocar o material no misturador novamente e adicionar o cimento;

Ligar o misturador em velocidade baixa e deixar por mais 4 min;

Após os 4 min, desligar o misturador, verificar se há material aderido ao fundo do misturador e extrair a argamassa final.

\subsubsection{Ensaios realizados}

\subsubsection{1 Índice de consistência}

Este ensaio foi realizado seguindo as prescrições da norma brasileira NBR 13276 em relação à argamassa dosada em obra e à base de cimento e cal hidratada, que consiste em pegar argamassa e, sob a mesa de índice de consistência umedecida, encher um moldetronco cônico, também umedecido, em três camadas de mesma altura. Com um soquete metálico aplicar 15, 10 e 5 golpes uniformes e homogeneamente distribuídos, respectivamente, nas primeira, segunda e terceira camadas. Após o enchimento, rasar toda a superfície do molde com uma régua metálica em movimentos curtos em vai-e-vem, e eliminar qualquer partícula em torno do molde com um pano. Acionar a manivela da mesa, de modo que a mesa suba e caia 30 vezes dentro de um período de $30 \mathrm{~s}$. Imediatamente após o fim das batidas, realizar com o auxílio de um paquímetro três medições em seu diâmetro. A média destas medidas representará o índice de consistência da argamassa. $\mathrm{O}$ 
resultado deste ensaio é apresentado por um valor unitário em milímetros, obtido através da Equação 01.

$$
\text { I.C. }=\frac{1^{\mathrm{a}}+2^{\mathrm{a}}+3^{\mathrm{a}}}{3}
$$

\subsubsection{Teor de ar incorporado e densidade de massa}

Este ensaio é descrito pela norma brasileira NBR 13278, que se resume na pesagem da amostra de argamassa acondicionada no molde cilíndrico de volume, aproximado, 400 $\mathrm{cm}^{3}$. O resultado do ensaio é expresso por um valor unitário em porcentagem, dado pela Equação 02.

$$
\text { A.I. }=100 x\left(1-\frac{A}{B}\right)
$$

Onde: A.I. - Teor de ar incorporado (\%); A - densidade de massa medida $\left(\mathrm{g} / \mathrm{cm}^{3}\right)$ dado pela Equação 03; B - densidade de massa teórica $\left(\mathrm{g} / \mathrm{cm}^{3}\right)$, dado pela Equação 04.

$$
A=\frac{M c-M v}{V r}
$$

Onde: Mc - Massa do Recipiente + Argamassa (g); Mv - massa do recipiente vazio (g); Vr - volume do recipiente $\left(\mathrm{cm}^{3}\right)$

$$
B=\frac{\sum M i}{\sum \frac{M i}{\gamma i}}
$$

\section{ANÁLISE E INTERPRETAÇÃO DOS DADOS}

\section{1 Índice de consistência}

Neste ensaio, foi verificado o índice de consistência em porcentagem. Comparando os valores do índice de consistência do traço de referência com os traços de 5, 10, 15 e 20\%, verificou-se um aumento gradativo acompanhando o aumento do teor de RCV. Destaque para o traço de $20 \%$ que apresentou um aumento mais representativo do que os demais, devido a redução da cal na argamassa. Estes dados estão representados pela Figura 2. 


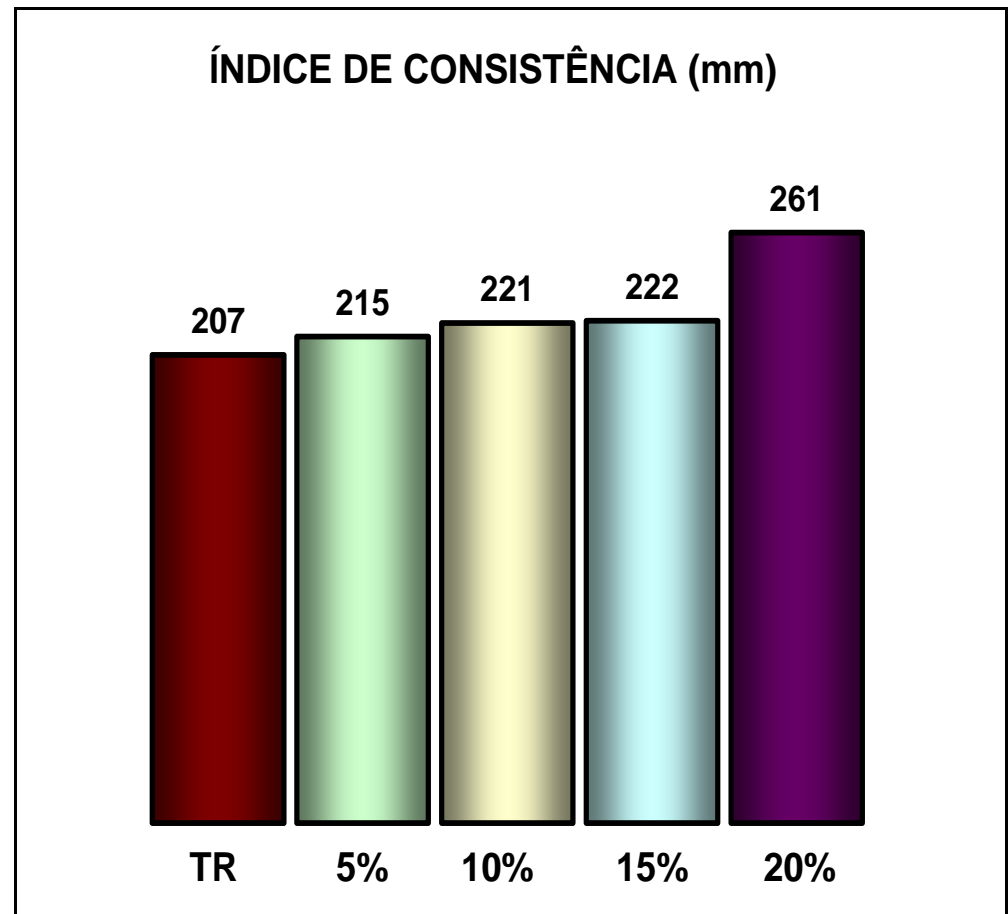

Figura 2 - Gráfico de avaliação do índice de consistência das amostras

\subsection{Teor de ar incorporado}

Assim como no ensaio de determinação do índice de consistência, o traço com 20\% apresentou um aumento de destaque em relação ao traço de referência. Os traços de 10 e $15 \%$ também apresentaram um aumento, porém o traço com 5\% apresentou uma redução no teor de ar incorporado. Os valores percentuais estão representados na Figura 3.

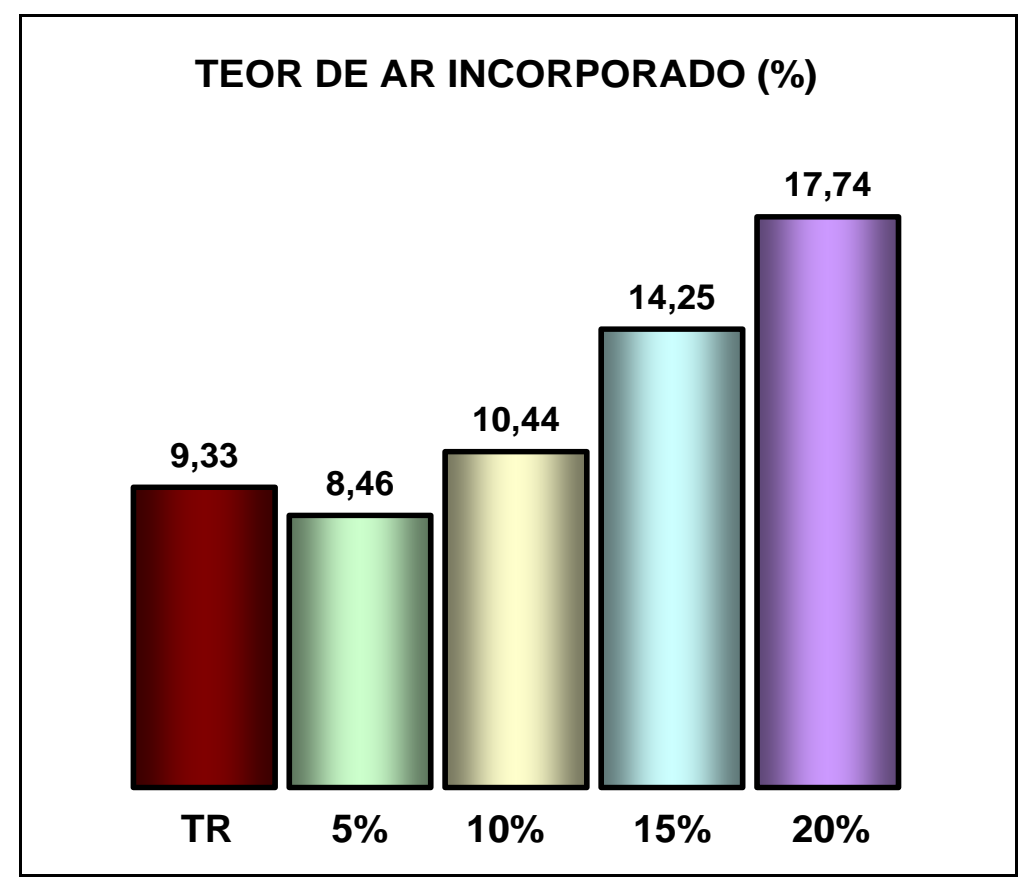

Figura 3 - Gráfico da Avaliação do teor de ar incorporado das amostras 


\subsection{Densidade de massa}

Como esperado, as amostras (10\%, 15\% e $20 \%$ ) que apresentaram altos valores de teor de ar incorporado, neste ensaio apresentaram uma redução de densidade. Por conseguinte, verificou-se no traço de $5 \%$ um aumento na sua densidade de massa. Os resultados estão representados na Figura 5.

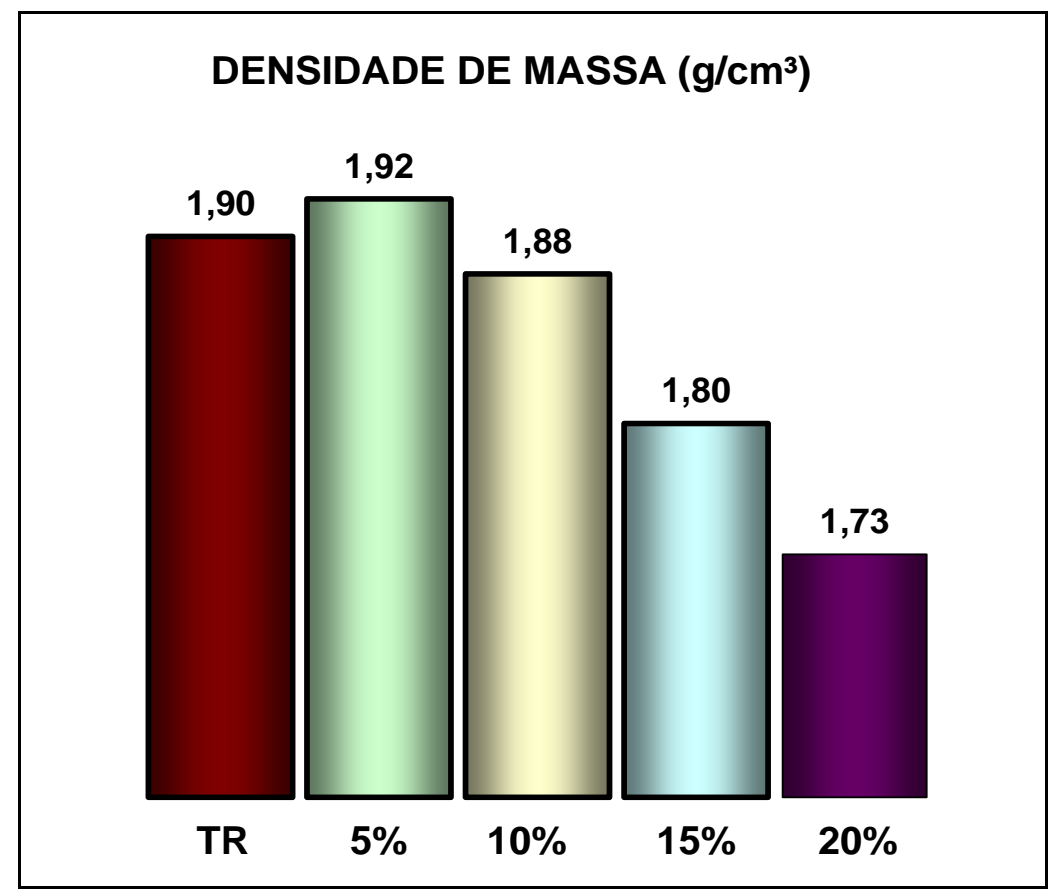

Figura 5 - Gráfico da Avaliação da densidade de massa das amostras

\section{CONCLUSÕES}

O presente trabalho foi desenvolvido através de experimentos e ensaios realizados em laboratório e investigaram o potencial de uso de resíduos de cerâmicas vermelhas recicladas provenientes da quebra ou empena de telhas de cerâmica vermelha como material de substituição parcial da cal na confecção de argamassas, visando avaliar as possibilidades de seu aproveitamento na construção civil. Dentro do escopo deste trabalho, as seguintes conclusões puderam ser extraídas a partir dos resultados obtidos:

- Todos os traços com adição de resíduos de cerâmicas vermelhas recicladas apresentaram um aumento no resultado do índice de consistência em comparação com o traço de referência;

- O teor de ar incorporado aumentou nos traços com 10\%, 15\% e 20\% de resíduos, enquanto que no traço com $5 \%$ de resíduos diminuiu;

- Os resíduos de cerâmicas vermelhas recicladas exerceram influência significativa na redução da densidade de massa no traço de $20 \%$, ou seja, a tendência é que quanto maior a adição de resíduos menor a densidade de massa da argamassa.

- Com o aumento do teor de substituição do resíduo houve uma melhora visual na coesão da argamassa. 
Por apresentarem valores de teor de ar incorporado próximo aos valores das argamassas convencionais e uma densidade de massa baixa, a argamassa estudada pode ser utilizada no mercado sem causar danos ou prejuízos à obra ou à construção.

\section{REFERÊNCIAS}

ASSOCIAÇÃO BRASILEIRA DE NORMAS TÉCNICAS. NBR 6474 - Cimento Portland e outros materiais em pó - Determinação da massa específica. Rio de Janeiro, 1984. de Janeiro, 1987.

NBR 7217: Agregados - Determinação da Composição Granulométrica. Rio

NBR 13276: Argamassa para assentamento e revestimento de paredes e tetos - Determinação do teor de água para obtenção do índice de consistência-padrão Método de ensaio. Rio de Janeiro, 2002.

NBR 13278: Argamassa para assentamento e revestimento de paredes e tetos - Determinação da densidade de massa e do teor de ar incorporado. Rio de Janeiro, 1995.

NBR 13281: Argamassa para assentamento e revestimento de paredes e tetos - Requisitos. Rio de Janeiro, 2002.

ÂNGUlO, S. C.; ZORDAN, S. E.; JOHN, V. M. Desenvolvimento sustentável e a reciclagem de resíduos na construção civil. PCC - Departamento Engenharia de Construção Civil da Escola Politécnica. Anais. São Paulo, 2001.

Coletânea Habitare - vol. 4 - Utilização de Resíduos na Construção Habitacional. ROCHA, J. C.; CHERIAF, M. Aproveitamento de resíduos na construção. 2004.

VIEIRA, A.A.P. Estudo do aproveitamento de resíduos de cerâmica vermelha como substituição pozolânica em argamassas e concretos. João Pessoa, PB. UFPB. Dissertação de mestrado. 2002.

COIMBRA. M. A.; DOS SANTOS.W. N.; MORELLI. M. R. Recuperação de resíduos inorgânicos para a construção civil (Recovery of inorganic waste for civil construction). Universidade Federal de S. Carlos - UFSCar. Departamento de Engenharia de Materiais - DEMa. Artigo. 2005

\section{AGRADECIMENTOS}

- Ao Departamento de Pesquisas do CEFET-RN;

- Ao Departamento Acadêmico de Construção Civil;

- Aos integrantes do Núcleo de Pesquisas; 